\title{
The Function Transition of Confucius Institute in the Internationalization of Chinese
}

\author{
Guangyu Zeng \\ College of Literature and Journalism, Sichuan University, Chengdu, Sichuan, 610064
}

Keywords: Chinese Internationalization; International Chinese; Confucius Institute;

\begin{abstract}
Confucius Institute's global layout is almost complete, from the number of growth into the quality and content to enhance the stage. In the internationalization of Chinese language, the function of Confucius Institute should also cultivate national Chinese teachers from the teaching of Chinese language, from the teaching of Chinese as a foreign language to the comprehensive study of Chinese international education system, from cultivating Chinese talents to cultivating international talents. Confucius Institutes should also play a greater role and value in cultural functions, economic functions and communication functions.
\end{abstract}

\section{Introduction}

Since 1989, the State Education Commission made it clear that "the teaching of Chinese as a foreign language is the cause of the state and the nation", the rapid development of teaching Chinese as a foreign language, the number and scale of studying abroad are increasing day by day. But to promote the Chinese to the international arena, so that the formation of the world "hot Chinese" phenomenon from the 2004 world's first Confucius Institute established. As of the end of 2016, the world has 140 countries and regions have established 513 Confucius Institute and 1073 Confucius Classroom. In 2016, the total number of students in various Confucius Institutes and classrooms reached 2.1 million, and nearly 70 countries included Chinese teaching in the national education system. That is, an average of more than 10 Confucius Institutes or Confucius Classrooms will be completed every month around the world. This is because the sustained growth of China's economy and the rapid promotion of China's international status have attracted the attention of the global people to learn Chinese, on the one hand because we actively implement the "going out" strategy, the use of Confucius Institute or Confucius classroom initiative to spread the Chinese culture And Chinese.

With the global layout of the Confucius Institute almost completed, the number of growth into the slowdown stage, its quality and content of the promotion is more important. The vigorous development of Chinese international promotion has provided opportunities for the development of Confucius Institute itself and challenged the function of Confucius Institute at present. We believe that the functions of the Confucius Institute also need to be transformed so as to better serve the international promotion of Chinese language and also serve the cooperation between China and foreign economic and trade fields and the construction of "one way".

\section{The Main Function of the Confucius Institute}

According to the annual report of Hanban for nearly 10 years, we can see that the main function of Confucius Institute is to work around several aspects of Chinese international teaching. Chinese international teaching links are the outline of the development, teaching materials, classroom teaching, performance testing. In 2007, Hanban issued the "International Chinese Language Proficiency Standard", "International Chinese Teacher Standard" and "International Chinese Teaching General Course Outline", a series of standards and outline reference to the rest of the world or language teaching framework, the first in the world Within the scope of the establishment of the Chinese syllabus. "Textbook development and promotion" and "Chinese test" is an 
indispensable part of the Confucius Institute's annual work report and is part of the main function of the Confucius Institute at present. And directly related to the function of classroom teaching, it is by the Confucius Institute several times a year to select Chinese teachers and Chinese volunteer teacher activities to achieve. In 2016, the Confucius Institute sent 9444 people to the world, of which 1073 teachers were sent to the "one country" country; 6071 Chinese teachers were sent to 130 countries, of which 2913 were sent to 413 Confucius Institutes (Classroom) people.

However, the Confucius Institute does not have its own full-time faculty, the above functions also rely mainly on the coordination of the university teachers, students to achieve. To a certain extent, the Confucius Institute is like a misunderstanding that is a teaching institution. This situation and predicament requires the transformation of the Confucius Institute function to open or crack.

\section{The Role of Confucius Institutes in Chinese Internationalization}

The internationalization of language refers to the process of a language becoming an international common language. International level of generalization can be divided into low-level (at least between the two countries), primary (common in several countries), intermediate (intercontinental or multinational international public domain) and advanced (internationally used). The internationalization of Chinese is the process of Chinese to the world, and it is also the process of Chinese as a communication tool widely used in the field of international public affairs. This process requires both economic, cultural and other factors, but also need to actively respond to Chinese, that is, "International Chinese".

Chinese is the language of the Han nationality and has many dialects. Therefore, the common language of the modern Chinese is based on the Beijing dialect as the standard sound, the dialect of the dialect in the north, and the typical modern vernacular as Mandarin. And Mandarin as a communication tool, but also the national statutory national language. It can be seen that the Chinese language from the language of the Han nationality to the universal language of the whole country is the normative process of the Chinese language itself. It is also the process of the Chinese language itself to adapt to the wider range of communication. Nowadays, Chinese is going to international, and the use of Chinese has gradually expanded to the international level, and the concept of "international Chinese" has gradually formed.

If "Chinese" belongs to the language of the Han nationality, then "Mandarin" belongs to the national common language, "International Chinese" belongs to all the world's language of Chinese language. Accordingly, we refer to the concept of "Dahua" proposed by Lu Jianming in 2005, that "international Chinese" is a Chinese language with a certain degree of flexibility in terms of vocabulary, vocabulary and grammar. It is in the voice of Mandarin as the standard, but in the soft, children and many other aspects of a certain degree of tolerance; in vocabulary to Mandarin standard vocabulary as the standard, while absorbing other Chinese community vocabulary; grammatical aspects of Mandarin grammar As the ideal standard, but the world of Chinese grammar variation has some tolerance. International Chinese is not the mother tongue of any person, it is by all the world's Chinese people together to form the communication language.

At this stage, we have the Confucius Institute as the main body in the world of Chinese teaching, this teaching behavior is generally referred to as "teaching Chinese as a foreign language." This name has been controversial, because it only emphasizes the "outside", ignoring the domestic minority areas such as non-Chinese language groups of Chinese language teaching. In 2012, the Ministry of Education merged "Chinese as a Foreign Language" and two other professions into "Chinese International Education". Since then, "Chinese International Education" has been common in all kinds of articles and books. In fact, this change, not only changed the name, even its connotation also changed.

First, the scope of "international" has changed. The goal of teaching Chinese as a foreign language is to cultivate talents who use Chinese to communicate faster and better. This target refers to the object is clearly Chinese as a second language learners, the object of communication is also directed to Mandarin Chinese people. However, to achieve internationalization of Chinese, not only is the Chinese language learners use Chinese to communicate with our Chinese people, but also the 
use of Chinese people in different countries to communicate the situation. That is, when the Chinese become international, airport, immigration, multinational corporations, the Olympic Games, the World Cup, international trade, international conference language, "international" is not only China and other countries, should also be between other countries and other countries "International". As English appeared in the process of globalization, "Chinese English" and "English" and other "World English", said the "Chinese English" Chinese and said "Indian English" Indians can use the "World English" International exchange and cooperation.

It is followed by the "education" of the main body changed. Before we carry out teaching Chinese as a foreign language or international promotion of Chinese, both in Putonghua as the standard from "inside" to "outside" promotion, and the difference between domestic Chinese teaching is different from the teaching object. At this stage, Hanban has tens of thousands of teachers and volunteers sent to Confucius Institutes around the world at this stage because the promoters of Chinese internationalization are our own and lack the participation of local Chinese teachers. The 11th Confucius Institute Conference in 2016 published the main tasks of the Confucius Institute, including the efforts to cultivate local Chinese teachers. At present, the scale of studying abroad at all levels of international education in China is increasing, especially in the "one way" country. In the future, there will be more and more people to become local Chinese teachers, engaged in Chinese international education. The addition of local Chinese teachers will undoubtedly help the process of internationalization of Chinese. However, there is no "international Chinese" vision, local Chinese teachers how to obtain the qualifications of Chinese proficiency? Or for those who have not yet reached the standard of local teachers to continue training, in time, until they meet the Putonghua standard and then posts. This will not affect the process of internationalization of Chinese? We can imagine that the process of Chinese internationalization, there will inevitably be such a situation: a non-native Chinese language teacher in non-Chinese language to teach some native speakers of non-Chinese students Chinese. (For example, a Chinese teacher from the United States whose teaches different nationalities in Italy.) At this point, they are engaged in Chinese international education, and the taught Chinese can only be "international Chinese". Local Chinese teachers and international Chinese teachers are not only "international Chinese" users, they are also "international Chinese" content providers.

Finally, "Chinese" itself is also international. Internationalization is a dynamic process and a two-way interaction process. Obviously, with the continued prosperity of the economy, China's internationalization is getting higher and higher. Along with the internationalization of its culture and language, the Chinese recorded and carried by the content in the internationalization process is also constantly "output" and "input". The contact between languages promotes the infiltration and fusion of language components. The pronunciation of "tea" in many languages around the world is similar to that of the Chinese dialect or the dialect of the Han dialect, which is the history of the internationalization of Chinese words. The increasing number of Chinese vocabulary is the performance of Chinese internationalization. Of course, the internationalization of language has never been a language one way to the world, but the language and other languages and multi-directional interaction process.

Chinese internationalization is bound to go through the process of contact with other countries, assimilation or alienation, and will inevitably form Chinese with local characteristics. These "Chinese" together constitute "international Chinese". We should not passively wait until the "international Chinese" with the process of internationalization of Chinese and gradually formed, should take the initiative to use "international Chinese" to promote the internationalization of Chinese.

\section{The Functional Transformation of Confucius Institutes}

Confucius Institute since 2004, the first time the Chinese teaching units built overseas, so that people around the world at their own house to learn Chinese. This move is undoubtedly great and correct so far, the number of registered students in the Confucius Institute around the world has so far increased. A large number of expatriate teachers and volunteers to meet the needs of Chinese 
learning at the same time, but also to the sustainable development of Confucius Institute has brought challenges. The term of office of a teacher (including a volunteer) dispatched from home and abroad is as short as one year and three to four years long. The mobility of the faculty is very large and is not conducive to the long-term stable Chinese promotion. Moreover, different teachers have different professional backgrounds, teaching ideas, teaching methods and preferences are not the same, for overseas learners, each round of teachers need to change the time to adjust the adaptation of the time. In addition, teachers sent from the country are not familiar with the country's education system, student characteristics, classroom management and other differences of factors, these factors undoubtedly bring a lot of difficulties to promote international Chinese. Training local Chinese teachers can maximize the avoidance of these problems. In contrast, we can see that the promotion of English in the world mainly depends on the non-English faculty of non-English speakers. For example, in China, people who are engaged in English teaching are mainly Chinese people, not from Speak English teacher. In other words, local Chinese teachers will be the main force of Chinese international promotion. If the Chinese language teaching is mainly borne by the local teachers, then this phenomenon is bound to the Confucius Institute is currently the main function of Chinese teaching challenges.

The Functional Transformation from the Teaching of Chinese is a Foreign Language to the Comprehensive Study of Chinese International Education. Chinese international promotion is not only depends on the continued prosperity of the economy, but also in the language standards and Chinese teaching standards has the right to speak. Standard construction requires practice, but also requires theoretical research. As mentioned earlier, the Confucius Institute's current teachers are scattered in schools and units. Academic background and research direction are not all in the international promotion of Chinese and it is difficult in the promotion of Chinese international research condensed into a strong talent team. In fact, the change in the name of the subject of Chinese international education is one of the changes from teaching to research. "Teaching Chinese as a Foreign Language" is based on our Chinese standard to "outside" promotion, therefore, in teaching is based on Mandarin as the standard. In teaching practice, the standard of Putonghua has caused many students to learn Chinese when they have a fear of psychological. Mandarin soft sound, children and other sound phenomenon is difficult to grasp, not only overseas students feel difficult, the Chinese dialect background of the Chinese people are difficult to fully grasp. If we blindly ask all Chinese learners according to standard Mandarin, it is bound that some people will be discouraged by Chinese. The "Chinese international education" is the name of the top designer reflects the international perspective. In this macro perspective, the "Chinese" promoted by the Chinese language is itself the Chinese language in the international range, that is, the language of the Chinese language, such as Lu Jianming (2005). The construction of the comprehensive system of Chinese international education has brought new tasks and research topics to the international promotion of Chinese language, which requires the functional transformation of Confucius Institutes.

From Cultivating Chinese Talents to Cultivating International Talents. The goal of Chinese teaching is to train talented people who are proficient in Chinese as soon as possible. This goal also reflects the fact that the Confucius Institute is currently cultivating Chinese talents, not international talents. This goal is not in line with the Confucius Institute's long-term development strategy. Confucius Institute is built by domestic universities or units and overseas universities or units. At present, it is mainly an international cooperation between colleges and universities. It can not locate its function in language teaching or training level, but should take the initiative to take higher education The task of cultivating talents. As the main body of Chinese language promotion, it can not only focus on cultivating talents for the development of Chinese services, but also should assume the responsibility of cultivating talents for the development of the world.

\section{Confucius Institute of Other Functions}

A culture of vitality is not only depends on inheritance and accumulation, but also rely on innovation and growth. Confucius Institute is the world to understand China's window, now to 
spread the Chinese culture-based. However, we spread or show the culture is mostly tai chi, paper cutting, Chinese knot, Peking Opera and other traditional culture, the introduction of Chinese culture are also excellent achievements in history, contemporary Chinese culture turn a blind eye. When the teachers of the Confucius Institute are proud to talk about the Chinese culture thousands of years ago, while practicing the "modernization" of the contemporary way of life, how Chinese culture persuasive? Moreover, the spread of culture, like knowledge, can be spread in any language as a carrier, it needs to silence the silent transmission, the need for words and deeds, the need to carry the language of the culture widely known. In the process of international promotion of Chinese language, we have made mistakes, that is, the use of "propaganda" to "promote" and "spread" and other words, due to improper translation of other countries caused by misunderstanding as "cultural aggression." This requires the Confucius Institute to earnestly assume the cultural function of the "Chinese Window", so that the world through the Confucius Institute to understand and learn Chinese culture.

Communication function. Confucius Institute to play a "bridge" role, to achieve communication function, in the introduction of the dissemination of China's outstanding culture, speak the story of China at the same time, but also to promote China and the country's outstanding cultural exchanges. Confucius Institute is not only the international cooperation, but also is the main body of international communication. Chinese and foreign personnel working in the Confucius Institute are engaged in cross-cultural communication and cross-cultural communication all the time in different cultural backgrounds. In addition to information communication, the Confucius Institute is also one of the platforms to deepen international understanding and enhance political communication.

Economic function. Language is the main tool to achieve communication, so Confucius Institute in teaching Chinese at the same time, but also to achieve the other functions. In particular, more than 100 countries and international organizations have actively supported and participated in the construction of "one way" since the CPC Central Committee has put forward the "One Way" initiative at the core of Comrade Xi Jinping. "Cooperation with the road" construction process, economic and trade cooperation is growing, and in cooperation, Confucius Institute can also play its economic function. Although the Confucius Institute is not directly involved in economic construction, but it is for the cooperation between China and the world in the training of language talent, high-end translation of talent, but also provide proficient Chinese people around the world of local talent. Confucius Institute can provide various language services to governments, enterprises, social institutions, etc., including language planning, language consultation, language education, language translation and language technical support, in order to achieve its economic function.

Confucius Institute is the product of Chinese international promotion, but also the main body of Chinese international promotion, the two relations is inseparable. The development of Chinese international promotion requires the Confucius Institute to continue to develop, but also requires its function as soon as possible transformation. The continuous development of Confucius Institute and functional transformation will also promote the promotion of Chinese in the international context and help the spread of Chinese culture in the world, to improve the Chinese and China's influence in the world.

\section{Acknowledgements}

This study was supported by the Ministry of Education Humanities \& Social Science Research Program of China (16YJC740002).

\section{References}

[1] Confucius Institute Headquarters. Confucius Institute Avenue Report, 2016 (63)

[2] Li Yuming. The Belt and Road Request Language to Pave the Way. China Daily, 2015 (9-22:7)

[3] Zeng Guangyu. On the Pronunciation of the Alphabetic Names in the Chinese Pinyin System Scheme. Journal of Chongqing Normal University Edition of Social Sciences, 2017 (3) 